\title{
Teoría general de sistemas en el diálogo del conocimiento campesino del altiplano cundiboyacense colombiano con las ciencias edáfica y climática
}

\section{GENERAL SYSTEMS THEORY IN THE DIALOGUE BETWEEN PEASANT KNOWLEDGE FROM THE COLOMBIAN ALTIPLANO CUNDIBOYACENSE AND CLIMATOLOGY/EDAPHOLOGY}

\author{
TEORIA GERAL DE SISTEMAS NO DIÁLOGO DO CONHECIMENTO \\ CAMPONÊS DO ALTIPLANO CUNDIBOYACENSE COLOMBIANO COM \\ AS CIÊNCIAS EDÁFICAS E CLIMÁTICAS
}

Pedro Simón Lamprea-Quiroga ${ }^{1}$

Rigaud Sanabria-Marin ${ }^{2}$
Para citar este artículo: Lamprea Quiroga, P., \& Sanabria Marin, R. (2020). Teoría general de sistemas en el diálogo del conocimiento campesino del altiplano cundiboyacense colombiano con las ciencias edáfica y climática. Perspectiva Geográfica, 25(2). 34-55. https://doi.org/10.19053/01233769.9283
Recepción:

15 de abril de 2019

Evaluación:

15 de agosto de 2019

Aprobación:

18 de noviembre de 2019

\section{Resumen}

En este artículo se analizan diferentes criterios, categorías y estrategias de las ciencias edáfica y climática frente al proceso de construcción de conocimientos tradicionales y científicos, los cuales son contrastados respecto a la erosión pluvial en el corredor Bogotá-Duitama del altiplano cundiboyacense en Colombia. En el análisis se aplican

1 Candidato a doctor en Geografía, convenio UPTC-IGAC. MSc en Ciencias Ambientales, con especialización en Ecología y Medio Ambiente. Ingeniero forestal. Grupo de Investigación en Geografía y Ordenamiento Territorial (GEOT). Consultor ambiental en proyectos de empresas del sector energético. Correo: pslamprea@hotmail.com.

2 Ingeniero de Sistemas. MSc y PhD en Geografía. Grupo de Investigación en Geomática y Ambiente (GIGA). Docente asociado, Universidad Pedagógica y Tecnológica de Colombia (UPTC). Correo: rigaud.sanabria@uptc.edu.co. 
herramientas de la teoría general de sistemas con el fin de facilitar la integración de explicaciones científicas a través del diálogo y la comprensión de las comunidades campesinas. Al integrar las variables culturales de la sabiduría campesina con el conocimiento científico se logra comprender y complementar las relaciones que intervienen en el entendimiento de la erosión del suelo a causa de la lluvia, en contraste con la variabilidad y los cambios climáticos representados en los cambios de la lluvia y las temperaturas extremas. El análisis sistémico de estos conocimientos permite incrementar la sinergia entre los enfoques cualitativo y cuantitativo, por tanto, se convierten en una herramienta útil para el análisis de enfoque mixto.

Palabras clave: cambio climático, conocimiento tradicional y científico, erosión pluvial, teoría fundamentada, teoría de sistemas, variabilidad.

\section{Abstract}

This article discusses criteria, categories, and strategies of edaphology and climatology for constructing traditional and scientific knowledge, which are contrasted for raindrop erosion in the Bogotá-Duitama corridor of the Altiplano Cundiboyacense, Colombia. The analysis applies tools of general systems theory to facilitate the integration of scientific explanations by dialoguing with and comprehending peasant communities. In incorporating the cultural variables of peasant wisdom into scientific knowledge, we can understand and complement the relationships involved in soil erosion due to rainfall, unlike climate change and variability represented by altered rainfall patterns and extreme temperatures. The systemic analysis of this knowledge increases the synergy between the qualitative and quantitative approaches; therefore, they become a useful tool for mixed approach analysis.

Keywords: Climate change, traditional and scientific knowledge, raindrop erosion, grounded theory, systems theory, variability.

\section{Resumo}

Neste artigo, analisam-se diferentes critérios, categorias e estratégias das ciências edáficas e climáticas frente ao processo de construção de conhecimentos tradicionais e científicos, os quais são contrastados com relação à erosão pluvial no corredor Bogotá-Duitama do altiplano Cundiboyacense na Colômbia. Na análise, aplicamse ferramentas da teoria geral de sistemas com o fim de facilitar a integração de 
explicações científicas por meio do diálogo e da compreensão das comunidades camponesas. Ao integrar as variáveis culturais da sabedoria camponesa com o conhecimento científico, é possível compreender e complementar as relações que intervêm na compreensão da erosão do solo por causa das chuvas, em contraposição à variabilidade e mudanças climáticas representadas nas mudanças da chuva e as temperaturas extremas. A análise sistêmica desses conhecimentos permite aumentar a sinergia entre as abordagens qualitativa e quantitativa, portanto, por isso, tornam-se numa ferramenta útil para a análise da abordagem mista.

Palavras-chave: mudanças climáticas, conhecimento tradicional e científico, erosão da chuva, teoria fundamentada, teoria de sistemas, variabilidade.

\section{Introducción}

De acuerdo con los estudios realizados sobre la degradación de los suelos por la erosión ${ }^{3}$ en los Andes colombianos, se encontró que más del 90\% de los suelos con vocación agrícola están afectados por dicho proceso en los departamentos de Boyacá y Cundinamarca (Ministerio de Ambiente y Desarrollo Sostenible [MADS] et al., 2015), lo cual conduce al deterioro de la base productiva campesina. Muchas áreas pueden llegar a condiciones de no retorno y, de esta manera, ahondar el deterioro edáfico agravado por limitaciones económicas, dificultades culturales en la comunicación, poca efectividad de las políticas e inconsistencia de los proyectos institucionales al no tener en cuenta múltiples factores que dependen de las mismas

3 "Degradación por erosión: pérdida de la capa superficial del suelo por acción del agua y/o viento, es mediada por el hombre, y trae consecuencias ambientales". Definición en consenso con los expertos reunidos en el 1er Taller Nacional sobre degradación de suelos y tierras (IGAC, Ideam \& MAVDT, 2010, p. 15). comunidades para avanzar en el control de la degradación en esta parte del país. Por su parte, en el conocimiento científico de la erosión pluvial poco se ha incluido el aspecto "subjetivo" de las comunidades rurales, situación que influye en la implementación de acciones efectivas cuando no corresponden a la visión y la percepción ${ }^{4}$ de la gente.

En dicho contexto es que se estudia la forma como los agentes sociales interactúan mediante sistemas adaptativos complejos y se relacionan mutuamente con los sistemas biofísicos en múltiples escalas temporales y espaciales para la comprensión de la erosión pluvial. Es decir, la investigación ${ }^{5}$ realizada pretende una revaloración del conocimiento campesino, apoyada con la sistematización

$4 \quad$ Por percepción se entiende la validación de las imágenes sensomotoras generadas internamente por medio de la información sensorial que llega del entorno. La base de la predicción -expectativa de eventos por venir-es la percepción (Llinás, 2001, p. 24).

5 Este artículo es parte del avance de la investigación doctoral en geografía que se adelanta en la UPTC-IGAC. 
de información para mejorar el diálogo entre los dos conocimientos, con mensajes capaces de reorganizarlo (Johansen, 1993) entre los agentes determinantes en el control de la erosión. Se buscan igualmente $\operatorname{los}$ criterios $^{6} \mathrm{y}$ las estrategias utilizadas por los agricultores para delimitar y diferenciar los procesos erosivos, todo esto para entender y buscar los puntos de encuentro que permitan complementar el conocimiento local o tradicional con el conocimiento ${ }^{7}$ científico. El estudio opta por colegir tres categorías complejas, lo cual incluso para la comunidad científica resulta poco estudiado al buscar las conexiones o enlaces entre las ciencias edáfica y climática con las formas de conocer y manejar el territorio rural.

Adicional a tales condiciones de deterioro edáfico, la complejidad de los impactos por una mayor variabilidad del clima y cambios climáticos ${ }^{8}$ reflejados en la precipitación y las temperaturas que se han evidenciado en una parte del altiplano cundiboyacense (Lamprea-Quiroga, 2013) son un desafío por resolver. Estos impactos del cambio climático, cuyos efectos podrían verse en la erosión pluvial, están en concordancia con los cambios que ocurren en los patrones de lluvia y temperatura y en el aumento de la ventosidad y la incidencia de la sequía, razón por la cual el clima y la erosión

6 Se adoptan las definiciones de la Real Academia Española (RAE, 2019) de criterio: 1) norma para conocer la verdad; 2) juicio o discernimiento; y estrategia: en un proceso regulable, conjunto de las reglas que aseguran una decisión óptima en cada momento.

7 En la epistemología se interroga, entre otros aspectos, sobre cómo la realidad puede ser conocida; la relación entre quien conoce y aquello que es conocido; las características, los fundamentos y los presupuestos que orientan el proceso de conocimiento y la obtención de resultados; y la posibilidad de que ese proceso pueda ser compartido y reiterado por otros a fin de evaluar la calidad y la confiabilidad de esos resultados (Vasilachis, 2009).

8 En este estudio se opta por la definición de cambio climático del Panel Intergubernamental del Cambio Climático (IPCC. 2014). tendrían efectos en los recursos hídricos y edáficos debido al incremento de tormentas en la mayoría de los procesos erosivos, a pesar de que en algunas áreas se contrarrestan las condiciones de humedad con las lluvias intensas (Bascher et al., 2012).

El problema de la investigación se resume en la pregunta: ¿cómo identificar, a través de criterios, categorías y estrategias, la sinergia que hay entre la percepción de los campesinos y el conocimiento que tienen los científicos de la erosión pluvial con respecto a la variabilidad y el cambio climático?

En el proceso se tiene en cuenta el enfoque y el tratamiento de los estudios humanos, en los cuales las personas no pueden ser tratadas todas las veces con los mismos razonamientos o consideraciones, como sucede en los desafíos ecosistémicos. Se parte de la base de que el hombre es en general independiente de las leyes o procesos que rigen tales equilibrios ecosistémicos. Si esto no fuera así, los problemas ambientales serían más sencillos de resolver porque las sociedades humanas, en el largo plazo, estarían fuertemente regidas por las mismas leyes que determinan el comportamiento de las demás especies. Una opción podría ser dejar que el proceso (problema) siguiera con el mismo ajuste delimitado por las leyes de la naturaleza (sabia y evolutiva) y esperar la respuesta con la respectiva degradación antrópica (erosión) y la afectación negativa del territorio. No obstante, debido a que el hombre en una generación humana modifica varias veces las leyes en función de su cultura y su provecho personal (muchas veces irracional), se debe abordar su estudio de manera diferente (León-Sicard, 2001). Efectivamente, el hombre parece no acoplarse a las leyes que rigen los sistemas vivos y, por tanto, no entra en el diseño de las leyes ecológicas (Ángel, 2012). 


\section{2. Área de estudio}

El corredor de estudio entre Bogotá y Duitama alberga costumbres representativas del altiplano cundiboyacense con sus prácticas agrícolas, en parte por la relativa homogeneidad geomorfológica o formas con declive gradual (fundamental para estudiar erosión pluvial y no complejizar el análisis con la remoción masal), rango altitudinal (entre 2.100 a 3.300 m s. n. m.) y diferentes grados de erosión del suelo. En dicho territorio se procura una mirada desde la ciencia geográfica para estu- diar una problemática compleja, la cual pretende articular o relacionar disciplinas de las ciencias naturales y sociales con análisis y enfoques que difícilmente se pueden abordar con los métodos de investigación lineal clásicos (Ossa, 2017).

El referente edáfico toma la información del estudio nacional de degradación de suelos por erosión en Colombia (MADS et al., 2015), a partir del cual se realizó la clasificación y distribución de las superficies con erosión en el área estudiada, lo cual se ilustra en la Figura 1.

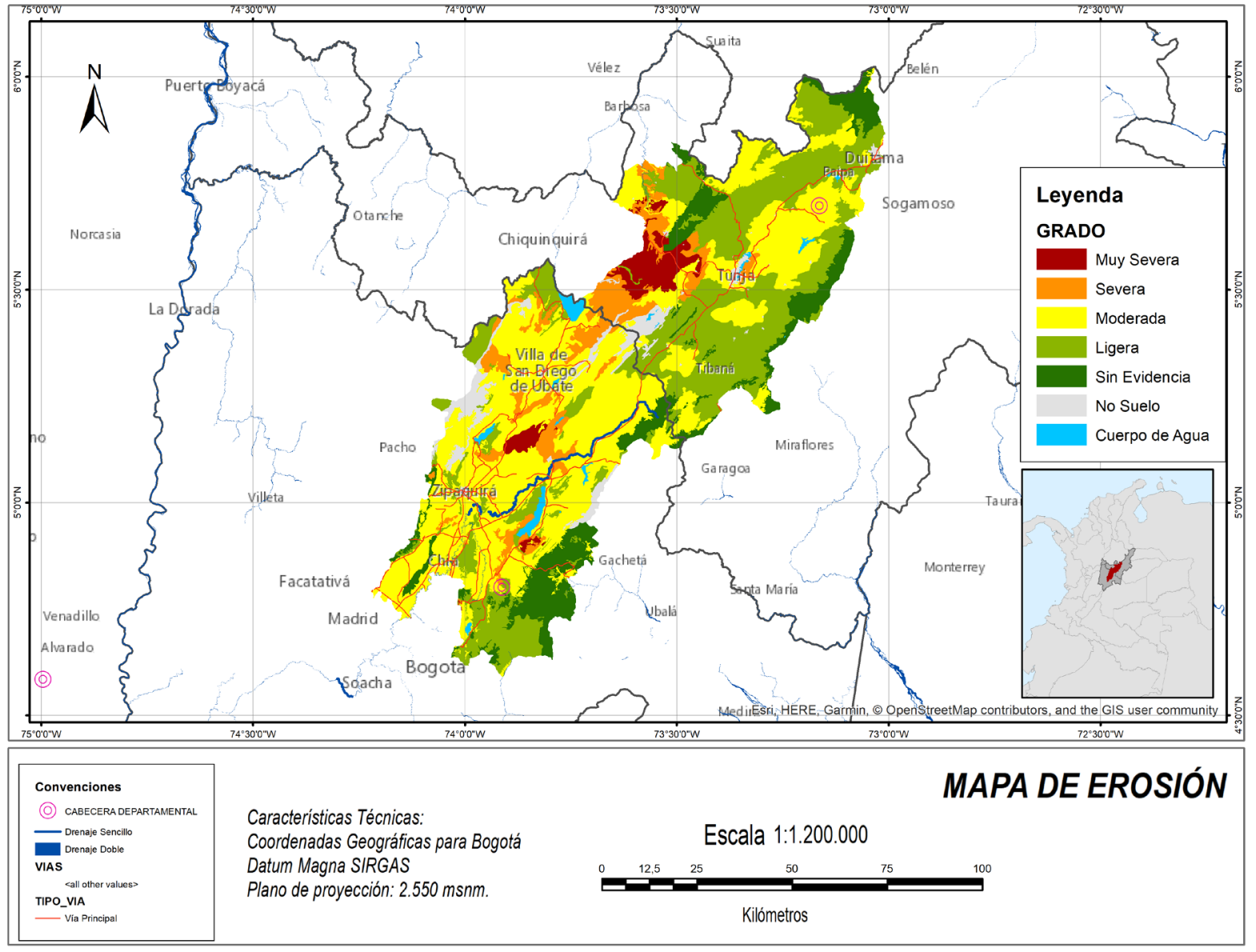

Figura 1. Distribución de la intensidad de la erosión

Fuente: elaboración propia con base en MADS et al. (2015). 
En la Figura 1 se ilustra la distribución de la erosión, en donde puede apreciarse en color rojo la categoría de erosión muy severa en inmediaciones del costado sur del embalse de Tominé (municipio de Guatavita, 755 ha) y en los municipios de Nemocón (2.428 ha), Tausa (1.078 ha), Suesca (766 ha), Cucunubá (332 ha) y Guasca (243 ha) en Cundinamarca, para un área cercana a 5.600 ha $(1,3 \%)$ del área estudiada, superficie que se incrementa más del 9\% cuando se suma a la erosión severa. En los municipios de Ráquira (7.117 ha), Sáchica (5.223 ha), Samacá (2.485 ha), Chíquiza (1.366 ha), Sora (1.335 ha), Villa de Leyva (1.288 ha), Gachantivá (932 ha), Santa Sofía (495 ha) y Cucaita (394 ha), que en conjunto alcanzan más de 20.570 ha $(5,5 \%)$ en el área estudiada en Boyacá, se supera el $12 \%$ cuando se incluye la categoría de erosión severa.

\section{Metodología}

Con el objeto de encarar tal complejidad se recurrió al uso, adaptación e integración de diferentes herramientas y enfoques cualitativos y cuantitativos que facilitaron el análisis y síntesis, para así llegar a la dilucidación y obtención de la respuesta a la pregunta de investigación.

\subsection{El análisis científico apoyado con la teoría de sistemas}

El análisis científico se apoya en los trabajos de Bertalanffy (1976) y Johansen (1993), compendiados en la teoría general de sistemas ${ }^{9}$ (TGS). En

9 El enfoque sistémico se caracteriza por realizar una serie de actividades o subprocesos que, en un orden predeterminado, están orientados al logro de un objetivo. Según Grant et al. (2001, p. 15), un sistema es un conjunto de procesos interconectados caracterizados por muchas vías recíprocas de causa y efecto.

Vol. $25 \mathrm{~N}^{\circ} 2$

julio - diciembre de 2020

pp. 34-55 la Tabla 1 se sintetizan los elementos y conceptos adaptados que se aplican en el análisis de las relaciones causales. Con tales elementos se asocian las variables para formular proposiciones que estructuran una argumentación, además de precisar conceptos y relaciones para constituir las categorías. El análisis se realiza, por tanto, con las herramientas de la teoría general de sistemas $^{10}$, la organización de forma compacta y relacional y las estructuras del modelo conceptual a partir de las funciones (procesos) relevantes del proceso erosivo para contrastar los dos conocimientos, el tradicional y el científico.

Con base en los elementos presentados en la Tabla 1, el ejercicio se enfoca en identificar las interacciones. Luego se van construyendo las relaciones, conceptos y teorías en una estructura de relaciones causa-efecto, las cuales se organizan en la matriz de relaciones causales (positiva o negativa); estas variables posteriormente son analizadas en la matriz de Vester (2014), para luego graficarlas en un plano cartesiano para facilitar su interpretación y evaluación conjunta.

El análisis científico del proceso erosivo tomó en cuenta las variables de los modelos de Morgan y Finney de 1984 y WEPP de 1989 (Tragsa et al., 1998). Con esta herramienta se muestran las relaciones causales de la erosión, donde se clasifican las variables de entrada, los procesos (acciones) y las salidas (perturbación final: erosión). Con esta base teórica se realizan interpretaciones que permiten organizar el fenómeno erosivo. Luego

10 Después del carácter reduccionista de las ciencias, se cambió al análisis fragmentado con métodos transdisciplinarios que dieran cuenta de la complejidad de los fenómenos desde diferentes perspectivas con distintas interrelaciones. Así nace la cibernética, la teoría de la información, la teoría de sistemas y la teoría de la complejidad (Ossa, 2017). 
se elaboran los modelos en los cuales se permite hacer una representación de nuestro campo de acción y ubicación en el mundo (Fourez, 1994).

Con base en la matriz de Vester, otra de las herramientas sistémicas (Vester, 2014; Cole, 2006) para el estudio de problemas complejos, se realiza el análisis de motricidad o predominancia de las variables a través de la evaluación comparativa del nivel del efecto de una variable sobre las de- más variables. El análisis de motricidad permite reflexionar y abstraer sus efectos sobre las variables a través y en conjunto ${ }^{11}$, para luego enfocar el esfuerzo hacia la calificación y la clasificación de variables dentro del análisis sistémico ${ }^{12}$. Este proceso permite cuantificar las diferentes interrelaciones entre las variables de manera cualitativa y cruzada con el juicio del experto, apoyado en la realimentación constante de las entrevistas para contrastar las variables.

TABLA 1. ELEMENTOS Y CONCEPTOS EMPLEADOS DE LA TEORÍA GENERAL DE SISTEMAS

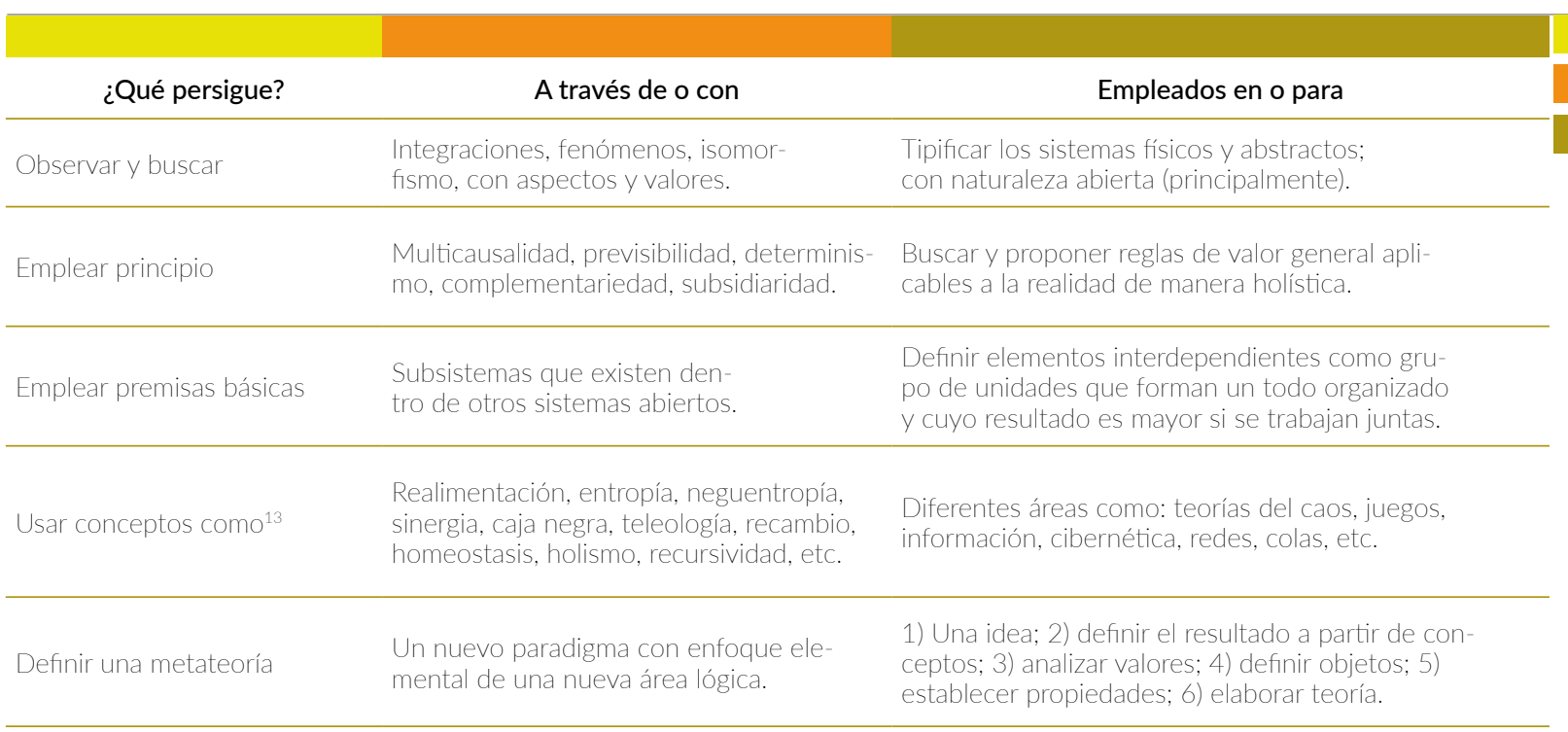

Fuente: elaboración propia a partir de Bertalanffy (1976) y Johansen (1993).

11 La valoración se realiza calificando de forma ordinal el nivel de influencia de una variable sobre las demás. De esta forma, aquellas variables que tienen alta influencia sobre las demás reciben una mayor valoración y son clasificadas como activas o autónomas. Si influyen sobre las demás y reciben además la influencia de aquellas, tienen una valoración alta tanto en la ordenada como en la abscisa y se clasifican como variables críticas. Las variables que reciben alta influencia de las demás (alta valoración en las abscisas) son clasificadas como reactivas; estas variables son usadas por excelencia para la elaboración de indicadores o la medición del resultado. Las variables con baja calificación en los dos ejes se denominan pasivas (Cole, 2006; Vester, 2014). El método para determinar los ejes que dividen el plano cartesiano (línea segmentada) se desprende del rango de los valores alcanzados en cada eje.
12 No debe confundirse el análisis sistémico con la sistemática; el segundo concepto se refiere a la clasificación.

13 Según Kant (1928, citado en Bertucci et al., 2013), la sensibilidad es la facultad por medio de la cual pasivamente se recibe la representación de las cosas que nos afectan. Es la capacidad (receptividad) de recibir representaciones por el modo como somos afectados por los objetos. Estas representaciones formadas son intuiciones empíricas. Es una relación inmediata con el objeto, que funciona como un medio para que el pensamiento se ponga en acción. No obstante, esta sensibilidad es insuficiente para producir conocimiento. Para generar conocimiento es necesario hacer juicios mediante el empleo de abstracciones asociadas con el entendimiento o facultad para relacionar conceptos que descansan en funciones. A su vez, los conceptos fundamentales del entendimiento permiten establecer categorías. 


\subsection{Proceso metodológico para comprender las relaciones desde el conocimiento campesino}

El marco general de realimentación entre los dos conocimientos se realizó con el diálogo estructurado $^{14}$ y con el acompañamiento de las actividades en la finca. Este diálogo fue previamente estructurado a modo de entrevista, pero sin tener un libreto fijo o rígido. Por el contrario, fue un trabajo iterativo de revisar permanentemente los análisis realizados con las herramientas de la teoría de sistemas, basados en los criterios y estrategias de los campesinos, lo cual se logra caracterizar con el trabajo de campo. Es necesario tener presente que el conocimiento para las comunidades locales, más que una pieza aislada y distante, configura todo un sistema con su forma de vida, dentro de una concepción holística en donde no existe separación entre hombre y naturaleza (Semanate \& León, 2012).

\subsection{El proceso dialógico con los campesinos}

En la aproximación y la comprensión de la erosión por parte los campesinos (asociado con las ciencias edáfica y climática) se toman en cuenta elementos de la teoría fundamentada (Strauss \& Corbin, 2002). Con este enfoque se busca clasificar, asociar, describir, sistematizar, relacionar y caracterizar los elementos a partir de las evidencias. El análisis cualitativo inicia con los datos recopilados de manera sistemática con el fin de ser analizados en tres componentes: 1) primero, los datos se obtienen de entrevistas, observaciones, documentos, sensores

14 Más de 30 diálogos realizados en los municipios de Sesquilé Nemocón, Sutatausa, Villa de Leyva, Suesca y Villapinzón, entre otros. Para tener una mejor georreferenciación ver la Figura 3. remotos, etc. 2) Segundo, los procedimientos que se usan en la investigación para interpretar y organizar los datos. Entre estos se encuentran procesos para conceptualizar y elaborar categorías en términos de sus propiedades y dimensiones, además de relacionarlos por medio de oraciones proposicionales (denominado codificar). Esto se apoya con las dos herramientas empleadas (relaciones causales y matriz de Vester). 3) El tercer componente lo conforman los escritos de artículos, libros y presentaciones.

Con las formulaciones y resultados encontrados, los cuales orbitan a lo largo de muchas cuestiones ${ }^{15}$, se nutre el proceso de investigación para aclarar y precisar los conceptos, delimitar las categorías y lograr los niveles de abstracción más generales. El énfasis del proceso consiste en precisar y avanzar en el análisis con la estructuración de los conceptos, relaciones y categorías, para posteriormente avanzar en el desarrollo de la teoría ${ }^{16}$. Esta forma de teorizar implica, además de concebir o intuir ideas (conceptos), formularlas en un esquema lógico, sistemático y explicativo (es decir que son llevados a la matriz de relaciones causales). Así, se utilizan los elementos de la teoría fundamentada o anclada, tomando en cuenta los trabajos de Strauss y Corbin (2002).

15 Algunas de las preguntas con las cuales se realiza el análisis detallado del fenómeno erosivo son: qué (acciones generadoras), por qué (razones), cómo (forma de interacción), cuánto (funciones asociadas), cuándo (tiempos, frecuencias), dónde (el territorio), quiénes (agentes, instituciones) y para qué (productos que explican el objetivo).

16 Para Strauss y Corbin (2002, p. 33), la teoría es un conjunto de categorías bien construidas, por ejemplo, temas y conceptos interrelacionados de manera sistemática por medio de oraciones que indican relaciones. Esto permite formar un marco teórico que explica el fenómeno social, psicológico, educativo o de otra clase. Las oraciones que indican las relaciones explican: quién, qué, cuándo, dónde, por qué cómo y con qué consecuencias ocurren los acontecimientos. Una vez que los conceptos se relacionan por medio de ciertas oraciones para formar un marco teórico explicativo, los hallazgos de la investigación pasan de ser un ordenamiento conceptual y se convierten en teoría fundamentada. 
Adicional a tal marco procedimental, es importante tener en cuenta que en la investigación social influyen las representaciones sociales (RS), lo cual obedece a una lógica inductiva, teniendo en cuenta que su punto de partida son las cogniciones relativas a un determinado objeto social que comparten miembros de una población homogénea en relación con dicho objeto (Abric, 2001). Es así como las RS constituyen al mismo tiempo un enfoque y una teoría (Banchs, 2000), lo cual, además de no ser un cuerpo teórico homogéneo, presenta diferentes modos de apropiación de la teoría. Estos modos se corresponden con el enfoque procesual, más interesado en el contenido de las representaciones en términos de su sentido y significado, junto con el enfoque estructural, que trata los mecanismos de organización de dichos contenidos.

En el proceso se tiene en cuenta que los conocimientos provenientes de distintas fuentes, a pesar de sus sucesivas transformaciones, no llegarán a articularse según las leyes del pensamiento lógicoformal (ciencia dura) para la comunidad. Así, para este conocimiento socialmente construido no es posible hablar de una estructuración en sentido piagetiano o en un sentido "fuerte" del término, y por lo mismo no es posible hablar de una integración y "equilibración progresiva" de los diversos conocimientos. Por esto no es posible calificarlo como desarrollo científico ${ }^{17}$. En tales diálogos con los campesinos para el levantamiento de información siempre se tuvieron en cuenta las adaptaciones particulares para mejorar la cualificación sin destruir ni sustituir la comprensión o el entendi-

17 La producción propia de las representaciones sociales (Lombardo \& Monchietti, 2015) es la "polifasia cognitiva". Esta implica la convivencia de imágenes, conceptos, explicaciones, etc., pertenecientes a niveles cognitivos de distinta riqueza, complejidad y origen sin que se forme una estructura articulada lógicamente según el método científico. miento campesino. El proceso teórico de la investigación se representa en la Figura 2.

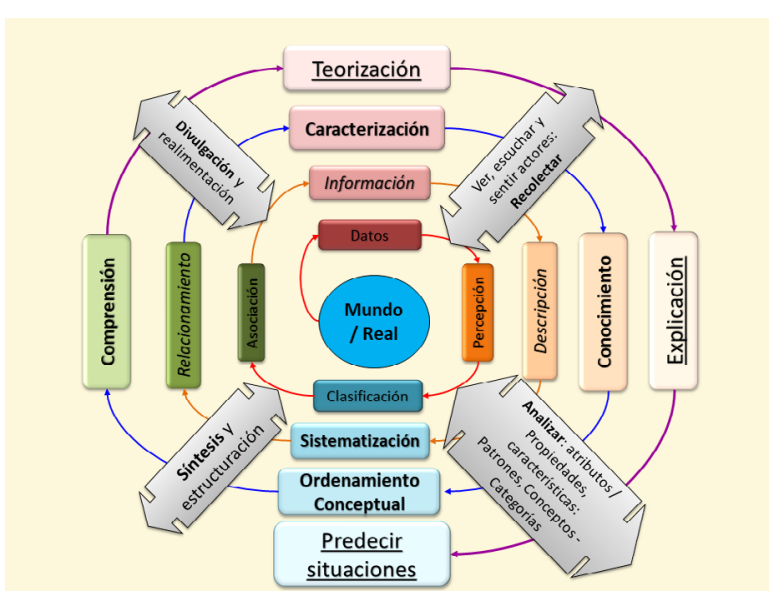

Figura 2. Niveles y pasos del proceso teórico

Fuente: elaboración propia con base en Strauss y Corbin (2002)

Tal procedimiento de levantamiento de información se hizo con diálogos estructurados, siguiendo el enfoque procesual de Araya (2002), además del análisis de contenido para dar cuenta del mensaje y el significado. Se destaca que dichos diálogos no se hicieron con la presión del lápiz y el papel, con preguntas y respuestas. Por el contrario, fueron conversaciones ${ }^{18}$ basadas en la discusión respetuosa, en la reflexión e interiorización por las partes ${ }^{19}$.

18 En el proceso, el investigador representa el "ojo de experto" en cuanto a las ciencias, lo cual significa que, cuando se habla de diálogos, estos son, en sí, el encuentro entre estas dos formas de conocimiento: científico y campesino (donde, de cierta manera, la relación entre el objeto de estudio y el sujeto que lo estudia se anula). Tales análisis, por la interacción entre el investigador y los datos, es al mismo tiempo arte y ciencia; sin olvidar que la ciencia puede considerarse como una empresa de normalización, en el sentido en que promueven en la sociedad una forma de ver y frecuentemente de actuar de forma uniforme (Fourez, 1994).

19 El estudio no se enfocó en medir los grados de erosión ni el nivel de conocimientos de los campesinos; los análisis se orientaron a identificar las conexiones y complementariedades de los dos conocimientos. Los diálogos buscaron mejorar la sinergia como parte de un proceso transcognitivo (resultado de la transdisciplinariedad) para entender mejor las relaciones entre las variables. Por tanto, no son procedentes los diseños de muestreo o el análisis estadístico. 


\section{Resultados y discusión}

Llamamos la atención sobre el hecho de que a pesar de realizar el proceso con gran contenido sistémico ${ }^{20}$, el estudio se realizó envuelto en el tejido sociocultural. De esta forma el proceso sobrepone permanente las diferentes variables analizadas, como parte de la energía que generan los espacios y los territorios por la práctica de las personas. Esto podría ser reinterpretado con una visión similar a la propuesta por Stock (2004) a partir de conceptos como: prácticas, distancia, calidad del lugar, paisaje, ubicación, diseño, orientación, accesibilidad, etc. ${ }^{21}$, estrategias que pesan mucho en las decisiones de las personas y por ende en la dilucidación del fenómeno estudiado. Esto muchas veces se muestra como un reflejo de las experiencias de vida y las expresiones colectadas de los entrevistados.

\subsection{El análisis científico apoyado con la teoría general de sistemas}

Para el análisis científico se estructuró un diagrama de relaciones causales ${ }^{22}$, según Aracil y Gordi-

20 La teoría general de sistemas es una amalgama de conocimientos que trata de la consideración global de los fenómenos que estudia, por contraposición al estudio de las partes para comprender el todo, que es la forma como la ciencia tradicional nos ha enseñado a desarrollar el conocimiento. En sentido estricto, no es una teoría científica sino más bien es un enfoque de sistemas que involucra una visión ampliada e interrelacionada de diferentes aspectos que determinan un fenómeno complejo que requiere la interdisciplinariedad (Ossa, 2017).

21 Se interpreta la vida como una práctica de vivencia de los lugares (Stock, 2004), además de ser expresión de la inteligibilidad de la espacialidad de los individuos. Esto a través de un triple análisis de la vida: las prácticas de lugar, formas de vida y los planes de vida (criterios para este estudio), todos con las interacciones con las demás personas, las cuales terminan aportando los valores de la cultura agrícola para la generación de su conocimiento tradicional.

22 La interacción de las variables en la Figura 3 parte de la identificación de relaciones y se basa en el concepto cibernético de "lazo de retroalimentación", el cual representa la influen- llo (1997), adaptado de los análisis de las variables estudiadas en los modelos de Morgan y Finney de 1984 y WEPP de 1989 (Tragsa et al., 1998). Tales relaciones causales se complementan con conceptos termodinámicos enfocados en la perturbación, el desorden, la organización, el equilibrio, el cambio y las adaptaciones, todos ellos enmarcados en las variables edafoclimáticas (véase la Figura 3). El cambio y la variabilidad climáticos (recambio para la teoría de sistemas) en la lluvia y la temperatura influyen sobre la variabilidad de la lluvia y la temperatura.

Las variables edáficas siguieron los criterios de los levantamientos de suelos (Instituto Geográfico Agustín Codazzi [IGAC], 2000; 2012) en función de la capacidad de almacenamiento de agua del suelo y porque al final representan la susceptibilidad a la erosión que poseen las tierras. Las variables con mayor capacidad de amortiguar la energía cinética de la lluvia dependen de las prácticas culturales en los cultivos, la capacidad de retención de agua en el suelo y la capacidad de intercepción de la lluvia por la cobertura vegetal, las cuales son clasificadas dentro los mecanismos de homeós$\operatorname{tasis}^{23}$. En consecuencia, las prácticas culturales en los cultivos son las adaptaciones y estrategias adoptadas hacia los cambios que se generan dentro del sistema. La función de adaptación estaría por cuenta de la evolución orgánica del ecosistema y

cia que puede ejercer un elemento sobre sí mismo, pero a través de su influencia en otros elementos. Ejemplo: comer en exceso puede causar aumento de peso. Los signos (+, -) o colores (azul y rojo) muestran el sentido del incremento o decremento respectivamente. Es decir, si aumenta la acción (color azul) se incrementa el efecto en forma positiva, mientras que el rojo se usa en sentido contrario (Ossa, 2017).

23 Los sistemas tienden a permanecer en cierto equilibrio (estadístico u homeostático). Parece existir una contradicción entre la tendencia al caos y la evolución que tiende a aumentar el grado de organización que poseen los sistemas (abiertos y los sistemas vivos), fenómeno que se encuentra en el principio de organicidad (Johansen, 1993, p. 118). 
también de la evolución cultural, relaciones que no nir de manera más efectiva para evitar la degradason excluyentes y serían las variables por interve- ción o perturbación del territorio.

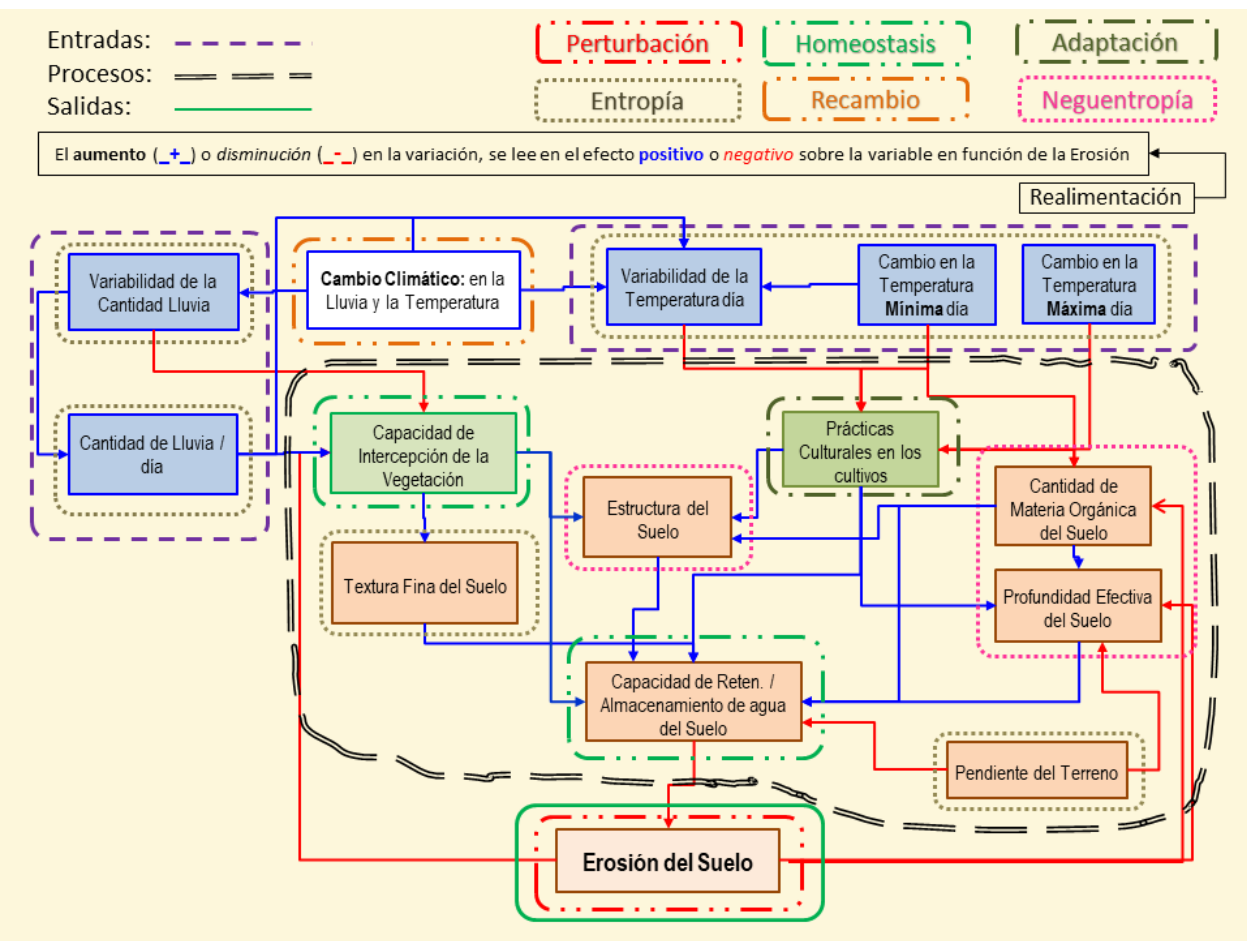

Figura 3. Relaciones causales de la erosión pluvial en función de las variables estudiadas

Fuente: elaboración propia con base en Aracil y Gordillo (1997), y los modelos de Morgan y Finney de 1984 y WEPP de 1989 (Tragsa et al., 1998).

En el modelo de la Figura 3, el coeficiente de infiltración del suelo depende de la capacidad de intercepción de la vegetación y la capacidad de almacenamiento de agua en el suelo, lo cual es fácil y claramente expuesto por los campesinos (ver más adelante). Las prácticas culturales en los cultivos determinan la capacidad de retención de agua en el suelo (absorber el agua de escorrentía) ${ }^{24}$. Por su parte, la capacidad de intercepción de la cobertura vegetal influye de manera sustancial en la capacidad de retención de agua por la biomasa forestal.

24 Estos conceptos y relaciones los saben los campesinos sin necesidad de conocer la teoría de sistemas.
De esta forma se destaca una de las funciones más importantes del ecosistema: retener parte de la lluvia entre sus ramas y hojas sin que llegue al suelo (esencia de la regulación hídrica y el control de la erosión). Esto podría llamarse ecohidrología a través de prácticas campesinas. Fonseca-Carreño et al. (2015) sugieren, a partir de estudios en Boyacá, la interdependencia entre prácticas agrícolas en los agroecosistemas con sus condiciones biofísicas y la situación socioeconómica de la familia. Por lo anterior, si no se quieren tener procesos erosivos, el manejo de la cobertura vegetal y el uso del suelo son los factores determinantes (adaptación). Hay que destacar que tales procesos de manejo hídrico 
son conocidos con exactitud por gran parte de los campesinos; no obstante, muchas veces no son valorados o entendidos por los profesionales con sus conocimientos adquiridos en las aulas.

La cantidad de materia orgánica, la profundidad efectiva y la estructura del suelo actúan como la neguentropía ${ }^{25}$ del sistema, ejerciendo su función a través de la capacidad de almacenamiento de agua en el suelo. El efecto inmediato es conducir el agua de manera controlada sin que se generen disturbios o pérdidas de las funciones y materiales del suelo; en otras palabras, controlan la erosión. Por tanto, en los desechos orgánicos y en todo aquello que se descomponga y se incorpore al suelo está la clave para que no se pierda parte de este con los nutrientes y se logre mayor productividad. Este conocimiento es valorado desde hace muchas generaciones y es uno de los criterios de los agricultores para mantener la productividad en sus cultivos de la manera tradicional. El resultado final de la decisión de la práctica en la finca se basa en una valoración entre productividad y cultura agrícola, lo cual depende en buena medida de la condición socioeconómica del campesino.

Lo atinente a la aculturación se desarrolla en buena medida por la "sustitución" de personas (o agricultores tradicionales), la introducción de nuevas formas de trabajar la tierra (tractor), la alteración de los equilibrios de poder (nuevos propietarios con casas de descanso), etc., como actores de las prácticas culturales en los cultivos. Al respecto, la cercanía y la facilidad de conexión con los grandes centros urbanos (Bogotá, Tunja, Duitama) van formando sus identidades como parte del proceso de las relaciones con otros, al ser en buena parte

25 La neguentropía (entropía negativa) es una medida de orden que debe extraer del medio (Johansen, 1993, p. 98).

Vol. 25 N. ${ }^{\circ} 2$

julio - diciembre de 2020

pp. 34-55 responsables por el pasado y por lo que son actualmente. Esto se refuerza con la evolución de los espacios-tiempos (Renaud, 2015) configurados por las carreteras construidas para el provecho de una demanda exagerada de bienes (centros de grandes consumos agravados por el modelo de productivo), que gravitan principalmente sobre Bogotá. Esta es una de las razones del corredor como eje vertebral por donde fluyen energías, productos, pensamientos, problemas y soluciones (véase la Figura 1).

Teniendo en cuenta la gran cantidad de variables y la complejidad de las interacciones, se buscó que los procesos de la investigación científica no riñan con los conceptos visibles para las gentes, las comunidades, las sociedades y los territorios. De no ser así difícilmente se encontrarían diálogos efectivos. Es decir, una buena opción es crear una entropía negativa (neguentropía) que oriente los análisis y síntesis, lo cual finalmente nos permite reorientar empíricamente (como sujetos pensantes) las gestiones sobre las variables más efectivas para controlar la erosión. Se encuentra entonces que lo subjetivo es inherente en el proceso objetivo para lograr un entendimiento más claro y efectivo de la erosión pluvial.

Por lo expuesto, en el marco conceptual se considera el proceso mental (estado y espacio funcional interno) como parte del avance evolutivo y la base para representar (o interiorizar) la realidad externa (percepciones) en los pensamientos (a partir de la integración de la motricidad organizada), para dirigir de esta forma el constante trabajo para predecir las acciones y los resultados en su entorno. Por consiguiente, se acepta y refuerza que la predicción (propósito esencial del conocimiento) es otra forma de ahorrar tiempo y energía (Llinás, 2001). Esto, en últimas, es la plataforma más robusta para 
aprender y generar conocimiento, bien sea que se enmarque en un método científico o como lo han hecho los seres vivos que dependen del movimiento (espaciotemporal) para mejorar y perdurar: por ensayo y error permanente a través de las experiencias que terminan consolidando la conducta y la cultura (en este caso, agrícola).

\subsection{Relación de las variables con la matriz de Vester a través del plano cartesiano}

El análisis de las variables (23 en total ${ }^{26}$ que se desprenden de las relaciones causales, con la posterior ubicación en el plano cartesiano (ver Figura 4), es la imagen científica de la forma como estas se interrelacionan. El análisis permite identificar las variables reactivas, las cuales son útiles como indicadoras (baja valoración en la ordenada y alta en la abscisa) y corresponden a la erosión pluvial, la escorrentía superficial y la estructura del suelo. En otras palabras, las variables reactivas son la respuesta y por ende son útiles para un proceso de monitoreo y evaluación.

Las variables con mayor valoración activa, como el número de días con lluvias, la variabilidad de la cantidad de lluvia diaria y la variabilidad de la temperatura diaria del aire, son los agentes de entrada más significativos en el proceso erosivo. Con base en los resultados de la matriz de Vester, se puede destacar el gran peso o explicación de

26 Una de las ventajas de tener un gran número de variables reside en la bondad de tener resultados que difícilmente se dejan influenciar por una calificación sesgada a una variable. Si bien resultaron 23 variables de las reflexiones en los diálogos y de los diferentes estudios (aunque se pueden agregar otras), el acotamiento se logra cuando la inclusión de la nueva variable no genera mayor influencia en las demás y esta se ubica dentro rangos bajos en el eje de la sumatoria de variables pasivas. El ejercicio tiende a la asíntota o saturación teórica (Strauss \& Corbin, 2002). erosión pluvial como un fenómeno preponderantemente climático, el cual termina siendo crítico una vez se sobrepasan los límites o niveles de protección sobre los cuales se tiene control (neguentropía con plazo). Véase más adelante el resultado de las variables críticas (prácticas culturales en los cultivos, capacidad de retención de agua en el suelo y capacidad de intercepción de la lluvia por la cobertura vegetal).

Las prácticas culturales aplicadas a los cultivos, la capacidad de intercepción de la lluvia por la cobertura vegetal, la capacidad de retención de agua en el suelo y el contenido de la materia orgánica del suelo alcanzaron alta valoración en la ordenada $(Y)$ y la abscisa $(X)$. Esto quiere decir que son variables que influyen mucho sobre las demás y a la vez reciben también mucha influencia de aquellas; por consiguiente, son variables críticas. Esta función, de cierta forma, tiene el efecto de absorber la energía cinética de la lluvia; esto se traduce o se refleja en una alta capacidad de amortiguación del efecto erosivo sobre el suelo. En todo caso, son estas variables sobre las cuales se puede gestionar y controlar la respuesta a la erosión (con mayor efectividad neguentrópica), toda vez que no es posible manejar hoy en día las otras variables activas.

Los resultados obtenidos en las variables críticas permiten clasificar y ponderar las variables mostradas en la figura de relaciones causales. Es decir, orientan la intervención para controlar el fenómeno erosivo (perturbación hacia el desorden). Con excepción de la intensidad máxima de la lluvia por día, la cual se incluye de forma implícita en la cantidad de lluvia por día ${ }^{27}$, se analizan en la matriz

\footnotetext{
27 El estudio utiliza la cantidad de Iluvia diaria y no la intensidad de la lluvia, teniendo en cuenta que en el país y la región estudiada no se cuenta con estos los registros con la densidad en el terreno y los largos periodos requeridos.
} 
(en donde se califican) todas las variables obteni- 1997), las cuales se grafican posteriormente en un das de las relaciones causales (Aracil \& Gordillo, plano cartesiano (véase la Figura 4).

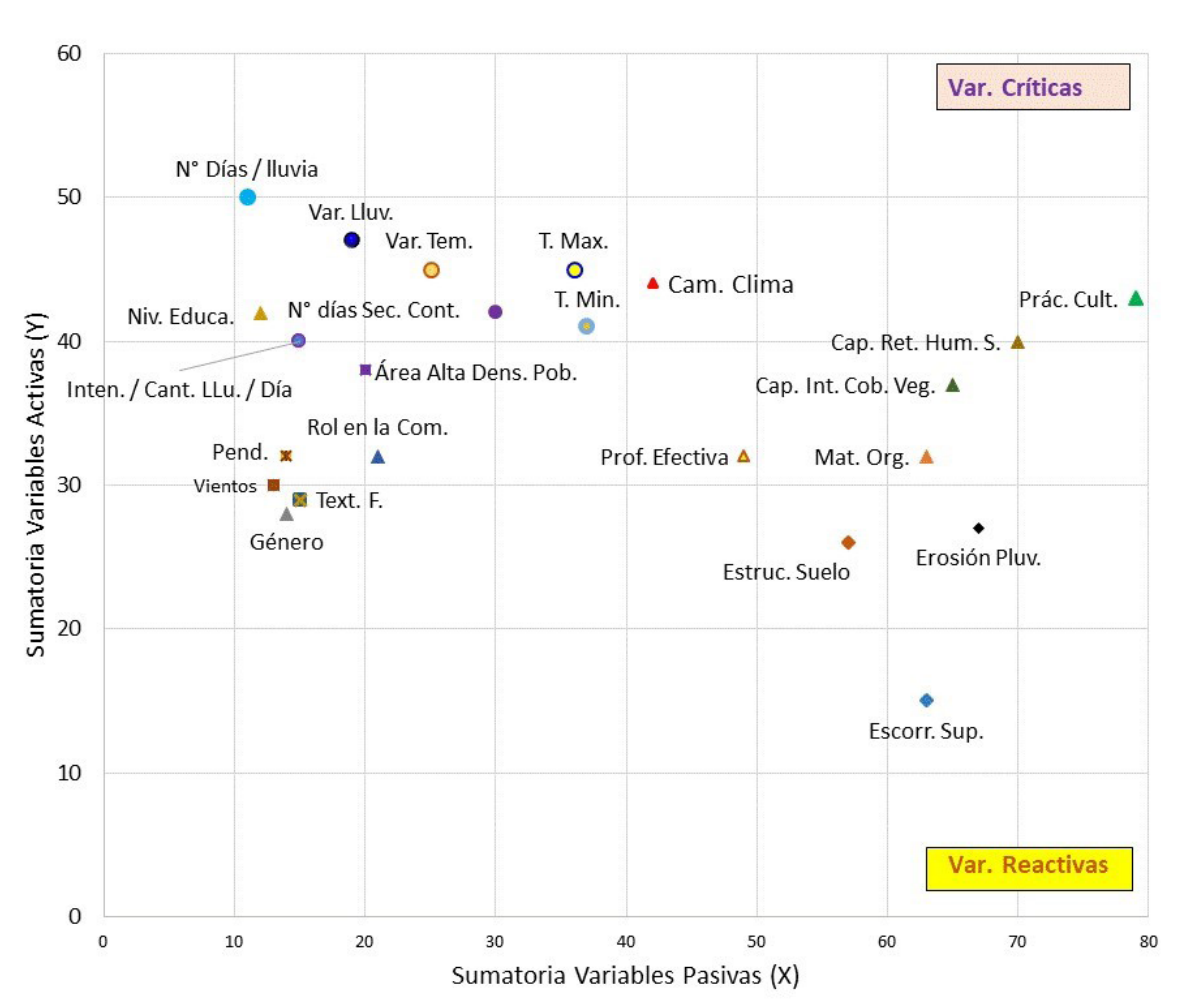

\author{
- Nº́as / lluvia \\ $\triangle$ Mat. Org. \\ - Erosión Pluv. \\ - Escorr. Sup. \\ * Pend. \\ - Inten. / Cant. LLu. / Día \\ $\triangle$ Prof. Efectiva \\ - Text. F. \\ - Estruc. Suelo \\ - Vientos \\ - Área Alta Dens. Pob. \\ $\triangle$ Prác. Cult. \\ $\triangle$ Cap. Ret. Hum. S. \\ - N días Sec. Cont. \\ $\triangle$ Cap. Int. Cob. Veg. \\ - T. Min. \\ OT. Max. \\ ^ Cam. Clima \\ o Var. Tem. \\ - Var. Lluv. \\ $\triangle$ Género \\ $\triangle$ Niv. Educa. \\ A Rol en la Com.
}

\begin{abstract}
Figura 4. Plano cartesiano con el análisis de motricidad de las variables generadas con la matriz de Vester
Variables: $n^{\circ}$ de días de lluvia ( $n^{\circ}$ días lluvia); materia orgánica del suelo (mat. org.); erosión pluvial (erosión); escorrentía superficial (escorr. sup.); pendiente (pend.); intensidad / cantidad de lluvia máxima en el día (inten. / cant. Ilu. / día); profundidad efectiva del suelo (prof. efectiva); textura fina (text. f.); estructura del suelo (estruc. suelo); vientos; área de alta densidad poblacional (área de alta dens. pob.; práctica en cultivos (prác. cult:; capacidad de retención de agua del suelo (cap. ret. hum. s.); $n^{\circ}$ de días secos continuos ( $n^{\circ}$ días sec. cont.); capacidad de intercepción de lluvia de la cobertura vegetal (cap. int. cob. veg.); temperatura mínima diaria (t. min.); temperatura máxima diaria (t. max.); cambio climático (cam. clima.); variabilidad de la temperatura (var. temp.); variabilidad de la lluvia (var. lluv.); género; nivel educativo (niv. educa.); rol en la comunidad (rol en la com.).
\end{abstract}

Fuente: elaboración propia.

Los vientos, la textura fina del suelo (arcillas, limos) y el género no alcanzan valores relativamente altos en la ordenada ni en la abscisa, por lo cual son clasificadas como variables pasivas. En consecuencia, no influyen ni se dejan influir por las demás variables analizadas.
El cambio climático (en este caso, la variación en el largo plazo de un elemento ${ }^{28}$ climático), como

28 Elemento climático: cualquiera de las propiedades o condiciones de la atmósfera que, tomadas en conjunto, definen el clima en un lugar determinado (por ejemplo, temperatura, humedad, precipitaciones). Tiempo atmosférico: estado de la atmósfera en un instante dado, definido por los diversos 
la temperatura máxima o mínima diaria, se ubican con valores moderadamente altos de las variables activas; por ende, reflejan su influencia en el fenómeno estudiado.

\subsection{Comprensión del problema con el conocimiento de los campesinos}

Uno de los problemas que se tiene de entrada es que gran parte de los campesinos no califican de la misma forma los factores y los agentes fisiográficos. En muchas ocasiones no se atreven a comparar situaciones de otros municipios o veredas lejanas, pues su conocimiento o entendimiento de los temas conversados en la mayoría de las situaciones se concretó solamente para lo que se presenta en su vereda o municipio. El fenómeno erosivo lo ven mejor desde el ámbito de la productividad.

Otro aspecto importante tiene que ver con la clasificación de los elementos climáticos realizada por los campesinos, los cuales se encuentran anclados en los métodos y criterios que les son útiles en sus actividades productivas. Con las mujeres el foco de conocimiento se encontró en la huerta y los animales menores, ya que es en estos espacios de la finca donde se refleja su organización y control. Esto nos lleva a entender que el fin último no es buscar la homogenización del conocimiento. Por tanto, debe tenerse en cuenta que al disminuir la variedad de conocimientos ${ }^{29}$, tal como ocurre con la biodiversidad, se disminuye una parte clave de la supervivencia; entonces se vuelve una forma

elementos meteorológicos (Organización Meteorológica Mundial [OMM], 2019).

29 Valladares y Olivé (2015) definen que los conocimientos tradicionales pueden expresarse con un lenguaje formal y sistemático que puede compartirse en forma de datos, fórmulas, especificaciones o procedimientos que han orientado exitosamente las acciones de comunidades, pueblos y naciones durante generaciones. de reducir las opciones para solucionar los problemas. Esto finalmente lleva a una "erosión del conocimiento".

\subsubsection{Percepción sobre el clima: lluvias y temperaturas}

Se reflexionó sobre múltiples expresiones del cambio del clima, principalmente en la intensidad de las lluvias con las tempestades, las bajas temperaturas, mayor cantidad de rayos, vientos desecantes y la sensación de calor al medio día, desde luego con los términos y nombres locales (vernáculos) asignados por cada campesino. Con tales criterios se tiene identificada por los campesinos la mayor variabilidad del clima en los municipios de Sesquilé, Sutatausa, Nemocón (Cundinamarca) y Villa de Leyva (Boyacá). En algunos casos se le llama "clima muy cambiante", "clima rebelde" o "clima loco". Tales cambios los han reconocido desde hace unos 15 a 30 años hacia atrás de manera diferenciada, es decir que no ocurren en todos los lugares del espacio estudiado.

En lo atinente a la forma como se percibe el clima, varios campesinos se refieren a la información recibida por la radio y la televisión (noticias principalmente). Asumen los comentarios que se repiten mucho (similar a la tiranía de la opinión mayoritaria) en los medios de comunicación sobre cambio climático, lo cual "dan por hecho" a pesar de no entender todos los comentarios u opiniones. Desde el conocimiento formal se entiende que tales mensajes llevan a la homogenización de los conceptos, incluso sin entenderlos suficientemente (emisor), los cual se traduce en una pérdida del conocimiento tradicional o pérdida de diversidad epistemológica (De Sousa Santos, 2010). 
La mayoría de los campesinos coinciden en que las lluvias de ahora son más fuertes y cambiantes. Identifican que antes (20 a 30 años) se podía hacer una mejor programación de los cultivos con la memoria de lo ocurrido en los dos o tres años anteriores. Añoran cómo antiguamente se podían utilizar las cabañuelas ${ }^{30}$, el almanaque Bristol y otras prácticas o métodos tradicionales que ahora no se usan. Creen que en algunos casos es por causa de las máquinas, pero principalmente porque "el clima ha cambiado mucho, ahora es muy variable y no se sabe o no se comprende cuándo va a llover”. Igualmente es claro para la gran mayoría de los campesinos "el incremento de la temperatura (hace 10, 20 o 30 años), que varía según el municipio o vereda, siendo más fuerte el calor si está despejado de monte". La altitud es fundamental para describir el efecto del cambio en las temperaturas del día y la noche. A medida que se desciende, los entrevistados destacan mayores variaciones en las temperaturas, lo cual también está relacionado, al parecer, con la mayor alteración o cambio de las coberturas vegetales naturales para establecer praderas o cultivos con mayores extensiones. Este fenómeno ha promovido el ascenso de las actividades agropecuarias como estrategia para el control de plagas y enfermedades, un ascenso paulatino que induce la erosión.

\subsubsection{Intensificación de las plagas y enfermedades}

Muchos de los campesinos fueron enfáticos en que las plagas y enfermedades se intensificaron y son

30 Las cabañuelas son asociaciones del comportamiento de las Iluvias diarias en los primeros días de enero con la secuencia mensual. Después, el día 13 vuelve a relacionarse (recabañuelas) con el mes de diciembre y así sucesivamente hasta llegar a enero en el día 24 de enero. Este instrumento, a pesar de ser controvertido para las ciencias atmosféricas, fue usado ampliamente hace varias décadas. más resistentes. Mencionan claramente la necesidad de usar líquidos o productos agroquímicos para poder cultivar y obtener una producción que les permita alcanzar alguna ganancia. Antes no era necesario porque se conocía mejor el clima. Evocan que cuando el tiempo no era "tan cambiante" la programación de las cosechas era más segura y fácil. "Ahora para poder producir y que la cosecha deje algo, toca echarle muchos líquidos ${ }^{31}$ '. Explican varios campesinos: "lo que más afecta con la variación del clima son las plagas por el hielo ${ }^{32}$ ". Reiteran que los incrementos en los costos de producción han sido en gran parte la causa para que se dejen cultivar muchas parcelas y especies. Este conocimiento del hielo, asociado con las heladas, se concreta de manera real y concreta en el cultivo, muy diferente a la abstracción de la ciencia meteorológica con el tiempo atmosférico. Vale la pena anotar cómo el conocimiento para el campesino tiene un propósito vital (se es lo que se cree), mientras el científico se puede quedar sin entender por no mover su frontera epistémica para acercarse a la idea o creencia campesina. Esto es pensar que debe prevalecer la distribución igualitaria del conocimiento científico y no al contrario, lo cual

31 "Los líquidos" es el nombre que los campesinos les dan a los agroquímicos que les aplican a los cultivos para el control de plagas y enfermedades. Estos productos son vendidos en las tiendas y muchas veces se aplican en cantidades y frecuencias que exceden ampliamente la dosificación técnica recomendada.

32 "El hielo" es un término empleado por los campesinos que incluye varios conceptos y categorías. Incluye un concepto muy relacionado con las condiciones de intemperie o el estado del tiempo atmosférico capaz de afectar negativamente los cultivos, es decir que se asocia con una categoría relacionada con las afectaciones a las plantas. El concepto abarca el tiempo atmosférico (intemperie) propicio para que baje la temperatura (heladas) en las noches con picos elevados a medio día, lo cual, con extremos de temperatura y humedad suficiente, facilita que las plagas y enfermedades ataquen a los cultivos. Es decir, no solo es el descenso y el incremento con extremos de temperatura la característica del fenómeno, pues si no afecta a los cultivos, no se considera "hielo". Este es su nivel de referencia y el método usado para determinar la variabilidad del clima. 
genera en cierta forma un pensamiento abismal, como lo señala De Sousa Santos (2010).

\subsubsection{Cambios en la cantidad y la disponibilidad de agua}

Los más conocedores indicaron la tala de la cobertura vegetal (monte) como causante de la pérdida de agua y suelo (erosión: menor producción) en las fincas, sin que se hiciera mayores cosas para ayudar a conservarla. No obstante, si bien reconocen los efectos dañinos de varias especies llevadas por el Gobierno con sus técnicos (como pinos y acacias), que "secan el suelo", no se quejan significativamente del eucalipto, pues para ellos significa el suministro de madera para diferentes usos en la finca, además de que representa una entrada económica, a diferencia de "la acacia que no sirve ni para leña". Se encontró una explicación generalizada en Nemocón sobre la causa por la cual el agua de los manaderos o nacimientos ha mermado e indican que al haber sembrado las acacias y eucaliptos en las fincas el consumo elevado de agua por dichas especies acabó con la abundancia de agua para las fincas. Dicen que esas especies dejan seca la tierra, no dejan crecer el monte a su alrededor ${ }^{33}$ y no se mantiene húmedo el terreno. Desde el conocimiento científico, prácticamente se expone un comportamiento alelopático sin que sea necesario realizar investigaciones complejas para llegar a tal resultado o evidencia expuesta por varios campesinos.

En Villa de Leyva (Boyacá) y la vereda Capilla Alta (vía a Arcabuco) se recibió una explicación de

33 Se encuentra que el campesino usa como indicador la presencia o ausencia de vegetación como medida de retención de agua en el suelo. Es, en sí, un método indirecto, sencillo y válido para evaluar la regulación hídrica. la pérdida de agua de forma permanente por causa de la tumba de monte. En general la función de la regulación del agua por la cobertura vegetal es clara, pues los campesinos dicen que "el monte llama el agua ${ }^{34 ",}$ lo cual expresa el efecto regulador del agua por la cobertura vegetal.

\subsubsection{Cambios en la erosión del suelo}

En las entrevistas realizadas en el municipio de Nemocón (Cundinamarca), diferentes campesinos destacaron la asociación entre la erosión y la entrada de especies forestales foráneas (acacias, eucaliptos y otras). Los procesos erosivos se atribuyeron siempre a causas ajenas a sus prácticas de manejo (principalmente a la naturaleza), situación que no pudieron cambiar una vez se perdió la tierra buena de cultivo. Se entendería entonces, para el primer aspecto, como un fracaso en el diseño o arreglo de las plantaciones más que en los materiales mismos, los que definen la funcionalidad.

Se expuso igualmente, por parte de otro agricultor, cómo las plantaciones de pinos y eucaliptos no permiten que la tierra se "mantenga", sino que, por el contrario, se compacta como la greda (formando pegotes) para luego resquebrajarse y perderse (erosionarse) la capa negra (horizonte orgánico superficial). En otras palabras, es pérdida de materia orgánica y estructura del suelo, proceso que científicamente fue explicado atrás. El mismo campesino explica cómo la presencia de suelos en contacto sobre lajas o planos impermeables (criterio) crea superficies que facilitan en deslizamiento en Chocontá (Cundinamarca). En términos científicos,

34 Este vocablo ("Ilamar agua") encierra todo un concepto ecológico de conservación (categoría), el cual es empleado por varios campesinos como criterio para conservar (regular) el agua y explicar el fenómeno de homeostasis. 
los conocimientos expuestos por los campesinos dejan en claro que las reforestaciones que emplean especies desconocidas (foráneas) generan graves impactos en el suelo, alterando fundamentalmente las relaciones edafohídricas de la cuenca y, por ende, agravando así los factores que gobiernan el proceso erosivo.

Un campesino del municipio de Sutatausa (Cund.) anota cómo el cambio con las nuevas personas que ahora están ingresando para "posesionarse del campo", con poca tradición y afán de producir, es otro factor que afecta las tierras. Se podría plantear entonces una erosión (pérdida) del conocimiento tradicional. Esto es desplazamiento, desaprendizaje, sin la utopía del interconocimiento: aprender sin olvidar lo propio (De Sousa Santos, 2010). Es, por tanto, una falla de las políticas públicas en el proceso de extensión agrícola, ya que en los centros de investigación no tienen en cuenta los conocimientos campesinos. Incluso las políticas que indirectamente dirigen fondos para cambiar sistemas tradicionales de cultivo pueden llevar a una pérdida del conocimiento local sobre el clima. Y tales prácticas son la base de las medidas de adaptación.

Diferentes campesinos de Villa de Leyva destacan que la explicación de la mayor erosión actual en las orillas de las quebradas es por la tumba de monte. "Esto hace también que las quebradas corran más rápido y también mermen más rápido el agua", dicen, sin dudar en la justificación. Partiendo de una base científica, tal explicación sencilla y compacta muestra la concordancia, a partir de la experiencia directa, de la función protectora y reguladora de la escorrentía por los bosques riparios (en bordes del cauce). Esto es toda una demostración empírica del control de torrentes con la eliminación de los picos o crestas en los hidrogramas de crecientes.

El uso del tractor para preparar los terrenos se encontró como una parte de la causa del daño o deterioro de las tierras en Nemocón. Se explicó que con el empleo de los bueyes, a pesar de ser más dispendioso y demorado, las tierras se conservaban mejor para la agricultura. El criterio empleado se basó en que el tractor deja la tierra como polvo. En Sutatausa se destaca el efecto negativo de introducir ovejos y chivos hace más de 30 años, que son animales que comen gran variedad de vegetación, incluso hasta la raíz (lo cual causa erosión).

\section{Conclusiones}

- El proceso de análisis con las herramientas de la teoría general de sistemas permite identificar las variables y relaciones, donde se concatenan las ideas, los términos, los conceptos y los argumentos que explican la producción de conocimiento local o tradicional en un contexto (cultural, social y económico) que es importante para entenderse entre las dos partes (ciencia y conocimiento tradicional).

- Las historias presentan evidencias de los aciertos y errores de las personas locales mayores en la comprensión de la erosión pluvial del suelo cuando se logra el diálogo abierto y transdisciplinar. Son un método efectivo para entender los criterios, las categorías y las estrategias de interrelacionamiento entre las ciencias edáficas y climáticas desarrolladas con el conocimiento tradicional. 
- El cambio del clima asociado estrechamente con la variabilidad climática se entiende claramente a partir de los mismos cambios introducidos por los campesinos en el uso y el manejo de los territorios, los cuales no escapan de las prioridades culturales o económicas.

- Entender la percepción de los campesinos a través de las prácticas culturales y sus explicaciones es un método útil para comprender y precisar las alteraciones generadas por la erosión, el cambio climático y la variabilidad climática. Es también una forma para complementar y mejorar la sinergia de las investigaciones científicas con el conocimiento local.

- Se identifican conocimientos campesinos que por su razón o interpretación solo se comprenden con sus valores y criterios, los cuales dependen del contexto sociocultural, histórico y geográfico, y un ejemplo de ello es la erosión pluvial. 


\section{Referencias}

Abric, J. C. (2001). Prácticas sociales y representaciones. Ediciones Coyoacán. https:// www.academia.edu/4035650/ABRIC_Jean_Claude_org_Practicas_Sociales_y_ Representaciones.

Ángel, C. (2012). El retorno de Ícaro. Muerte y vida de la filosofía, una propuesta ambiental ( $3^{a}$ ed.). Universidad Nacional de Colombia, IDEA. https://transecos.files.wordpress. com/2014/04/el_retorno_de_icaro.pdf.

Aracil, J. \& Gordillo, F. (1997). Dinámica de sistemas. Alianza Editorial S. A.

Banchs, M. A. (2000). Aproximaciones procesuales y estructurales al estudio de las representaciones sociales. https://www.researchgate.net/publication/285299738_ Aproximaciones_Procesuales_y_Estructurales_al_estudio_de_las_Representaciones_ Sociales.

Bascher, L., Elliot, S., Hughes, A., Tait, A., Page, M., Rosser, B., ... \& Jones, H. (2012). Impacts of climate change on erosion and erosion control methods - A critical review. MPI Technical paper N²012/45. Ministry for Primiry Industries. https://www.mpi.govt. nz/dmsdocument/4074/direct.

Bertalanffy, L. (1976). Teoría general de los sistemas. Fundamentos, desarrollo, aplicaciones. (Trad. de J. Almeda). Fondo de Cultura Económica S. A. de C. V. https:// cienciasyparadigmas.files.wordpress.com/2012/06/teoria-general-de-los-sistemas_-fundamentos-desarrollo-aplicacionesludwig-von-bertalanffy.pdf.

Bertucci, A., Solas, S. \& Oller, A. (2013). Introducción a la filosofía y a la argumentación filosófica. Edulp.

Cole, A. (2006). The influence matrix methodology: a technical report. https://icm. landcareresearch.co.nz/knowledgebase/publications/public/iMatrix_Tech_Report. pdf.

De Sousa Santos, B. (2010). Más allá del pensamiento abismal: de las líneas globales a una ecología de los saberes. En Descolonizar el saber, reinventar el poder (pp. 29-61). Ediciones Trilce. http://www.boaventuradesousasantos.pt/media/Descolonizar\%20 el\%20saber_final\%20-\%20C\%C3\%B3pia.pdf.

Fonseca-Carreño, J., Cleves-Leguízamo, J. \& León-Sicard, T. (2015). Evaluación de la sustentabilidad de agroecosistemas familiares campesinos en la microcuenca del río Cormechoque, Boyacá. Ciencia y Agricultura, 13(1) 29-47. https://revistas.uptc.edu. co/index.php/ciencia_agricultura/article/view/4804.

Fourez, G. (1994). La construcción del conocimiento científico. Sociología y ética de la ciencia. ( $3^{\mathrm{a}}$ ed.). Narcea.

Grant, W., Marín, S. \& y Pedersen, E. (2001). Ecología y manejo de recursos naturales: análisis de sistemas y simulación. IICA - Agroamérica.

Grupo Intergubernamental de Expertos sobre el Cambio Climático (IPCC). (2014). Cambio climático 2104. Informe de síntesis. Contribución de los grupos de trabajo I, II y III 
al Quinto Informe de Evaluación del Grupo Intergubernamental de Expertos sobre Cambio Climático. (R. K. Pachauri \& L. A. Meyer, eds.). IPCC. https://www.ipcc.ch/site/assets/ uploads/2018/02/SYR_AR5_FINAL_full_es.pdf.

Instituto Geográfico Agustín Codazzi (IGAC). (2012). Estudio detallado de suelos escala 1:10.000 de las áreas planas de los municipios de Sopó, Tocancipá, Gachancipá, Chía, Cajicá, Facatativá, Mosquera, Funza, Madrid, Bojacá y Soacha. [Convenio Ministerio de Ambiente y Desarrollo Sostenible, CAR, Gobernación de Cundinamarca e IGAC]. IGAC.

Instituto Geográfico Agustín Codazzi (IGAC). (2000). Estudio general de suelos y zonificación de tierras de Cundinamarca. (2 tomos). IGAC.

Instituto Geográfico Agustín Codazzi (IGAC), Instituto de Hidrología, Meteorología y Estudios Ambientales (Ideam) \& Ministerio de Ambiente, Vivienda y Desarrollo Territorial (MAVDT). (2010). Protocolo de degradación de suelos y tierras por erosión. Bogotá: IGAC, Ideam y MAVDT.

Johansen, O. (1993). Introducción a la teoría general de los sistemas. Limusa. https://www. academia.edu/8345344/1._Introduccion_a_la_Teoria_General_de_Sistemas_-_ Oscar_Johansen?auto=download.

Lamprea-Quiroga, P. S. (2013). Evaluación de la variabilidad de la lluvia diaria, la amenaza a la erosión pluvial y su relación con el cambio climático en el nororiente de Cundinamarca. Tesis de maestría, Universidad de Bogotá Jorge Tadeo Lozano.

León-Sicard, T. (2001). Ecología humana y ambientalismo: dos aproximaciones diferentes a las relaciones ecosistema-cultura. Gestión y Ambiente, 4(1), 49-55.

Lombardo, E. \& Monchietti, A. (2015). Niveles de conocimiento que integran las representaciones sociales. Un estudio sobre polifasia cognitiva. Perspectivas en Psicología: Revista de Psicología y Ciencias Afines, 12(2), 50-56. http://www.uacm.kirj. redalyc.redalyc.org/articulo.oa?id=483547667006.

Llinás, R. R. (2001). El cerebro y el mito del yo. El papel de las neuronas en el pensamiento y el comportamiento de los humanos. ( $2^{a}$ ed. en español, trad. de E. Guzmán). Norma.

Ministerio de Ambiente y Desarrollo Sostenible (MADS), Instituto de Hidrología, Meteorología y Estudios Ambientales (Ideam) \& Universidad de Ciencias Aplicadas y Ambientales (UDCA). (2015). Estudio nacional de la degradación de suelos por erosión en Colombia. Ideam.

Organización Meteorológica Mundial (OMM). (2019). Meteoterm. Base de datos terminológica de la OMM en seis idiomas. https://public.wmo.int/es/recursos/ meteoterm.

Ossa, C. (2017). Teoría general de sistemas. Conceptos y aplicaciones. Universidad Tecnológica de Pereira.

Real Academia Española (RAE). (2019). Diccionario de la lengua española (23a ed.). https:// dle.rae.es/. 
Renaud, A. (2015). Espacio y territorio, la necesidad de una definición crítica. Revista Carne Negra, Fanzine 4, 72-81. https://carnenegrafanzine.files.wordpress. com/2016/04/2015-carne-negra-fanzine-4-pdf.pdf.

Semanate, H. \& León, F. (2012). El conocimiento vernáculo como generador del desarrollo local. Perspectiva Geográfica, 17, 259-281.

Stock, M. (18 de diciembre de 2004). L'habiter comme pratique des lieux géographiques. EspacesTemps.net. http://www.espacestemps.net/articles/habiter-comme-pratiquedes-lieux-geographiques/.

Strauss, A. \& Corbin, J. (2002). Bases de la investigación cualitativa. Técnicas y procedimientos para desarrollar la teoría fundamentada. ( $1^{a}$ ed., trad. de E. Zimmerman). Universidad de Antioquia. https://diversidadlocal.files.wordpress.com/2012/09/basesinvestigacion-cualitativa.pdf.

Tragsa, Tragsatec \& Ministerio de Medio Ambiente (1998). Restauración hidrológica forestal de cuencas y control de erosión. (2ª ed., dir. de F. López). Grupo Mundi-Prensa.

Valladares, L. \& Olivé, L. (2015). ¿Qué son los conocimientos tradicionales? Apuntes epistemológicos para la interculturalidad. Revista Cultura y Representaciones Sociales, 10(19), 61-101. http://www.journals.unam.mx/index.php/crs/article/view/52005.

Vasilachis, I. (2009). Los fundamentos ontológicos y epistemológicos de la investigación cualitativa. Forum: Qualitative Social Research, 10(2). http://dx.doi.org/10.17169/fqs10.2.1299.

Vester, F. (2014). Malik Sensitivity Model the Computerized System Tools for a New Management of Complex Problems. http://www.frederic-vester.de/uploads/ InformationEnglishSM.pdf. 